\title{
Fault Diagnosis in Mixed-Mode Circuit By using Artificial Neural Network Method
}

\author{
S. Ramya, M.Meenaakumari, R. Hema
}

\begin{abstract}
In these work it is said that artificial systems are connected to finding of calamitous imperfections in the advanced piece of a nonlinear blended mode circuit. The methodology is exhibited on the case of a moderately mind boggling sigma-delta modulator. A lot of shortcomings are chosen first. At that point, issue lexicon is made, by reproduction, utilizing the reaction of the loop path to an info incline flag. This spoken to type of a carry-into table. Counterfeit neural system is then prepared for displaying (retaining) the look-into table. The conclusion is carried out so the artificial neural network is energized by broken reactions so as to introduce the deficiency codes at its yield. There were no blunders in recognizing the shortcomings amid conclusion.

Keywords: Fault Diagnosis, artificial neural network
\end{abstract}

\section{INTRODUCTION}

Each mind boggling framework is subject to issues or disappointments. In most broad terms an issue is any adjustment in a framework that keeps it from working in the best possible way. We characterize determination as the errand of distinguishing the reason for a deficiency that is showed by some watched conduct[1],[3],[5]. At that point some technique for figuring out what flaw has happened is required. This is frequently viewed as a two-arrange process: right off the bat the way that deficiency has happened must be perceived - what is alluded to as flaw discovery. Besides, the nature ought to be resolved with the end goal that proper healing activity might be started.

The blast of coordinated circuit innovation has carried with it some troublesome testing issues. The ongoing development of blended simple and advanced circuits confounds the testing issue much further. It ends up being progressively convoluted to choose a great deal of information test Artificial Neural Networkers and yield estimations that will give an abnormal state of weakness narrows savagery. There is in like Artificial Neural Networker an arranging issue of checking the loop path even on the speediest motorized elements.

Revised Manuscript Received on August 22, 2019.

S. Ramya , Department of Electronics and Communication Engineering, Bharath Institute of Higher Education and Research, Chennai, Tamilnadu, India. E Mail - ramyasamdra@gmail.com

M.Meenaakumari, Department of Electronics and Communication Engineering, Bharath Institute of Higher Education and Research, Chennai, Tamilnadu, India. E Mail - meenumathi.m@gmail.com

R. Hema, Department of Electronics and Communication Engineering, Bharath Institute of Higher Education and Research, Chennai, Tamilnadu, India. E Mail -hemrbujradha@gmail.com
In this work, they demonstrate that feed-forward artificial neural network might be connected to the finding of non-straight powerful electronic loop path that are blended with computerized first. So as to make the clarification more obvious, just a decreased arrangement of deficiencies will be utilized for example disastrous imperfections in the advanced piece of the converter. Just isolated deficiencies are reviewed.

This propagation before test thought was gotten. This infers consequent to picking the plan of inadequacies of interest (say the no doubt ones), dull reenactment is performed to make the structure response for every insufficiency. Codes are identified with the responses and used as a noteworthy part of the lack dictionary that, in addition, contains the faulty responses themselves. Of cause, the responses are addressed in a structure that is definitely not hard to control.

The artificial neural network is first prepared for displaying the look-into table[2],[4],[6] . This implies flawed reactions are over and over conveyed to the info, while the artificial neural network is compelled to introduce the issue codes at its yield. At that point, the artificial neural network running with the given vector of boosts (estimated yield signs of a defective or, potentially, flaw free framework) might be seen as pursuit of the look-into table. The artificial neural network reaction, if the system appropriately prepared, will promptly discover the deficiency and produce the shortcoming code at its yield.

This methodology connected is by the way of explaining the inserted system to simple electronics circuit design in [I]. As far as anyone is concerned this is the principal utilization of artificial neural networks conclusion of blended flag circuit submission.

\section{DESCRIPTION OF ANALYSIS METHODS}

Other than the mortal living master who is normally playing out the indicative undertaking, devices that will help, and what is most wanted, will execute determination naturally. These devices are an incredible test to configuration designs that relates to the way by and large the indicative issue is vague. Likewise, it is a deductive procedure with one lot of information making, all in all, boundless number of theories along which one should endeavor to discover the mixture. Thus the reason perpetual consideration of the examination network is pulled in by this issue [II].

Amid the wheel of life process of an item, checking and verification is done and applied in all the two states. That is the generation stage

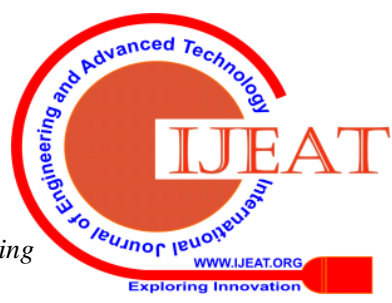


and the application stage. We guarantee, nonetheless, that the manageability of items is firmly affected by the plan stage. Along these lines, to make a maintainable item, one should structure the test professional and blend test flags from the get-go in the plan stage[7],[9],[11]. It is every now and again conceivable to perform practical verification of the framework. That, most much of the time, happens when few information/yield terminals is available. In most of cases be that as it may, full practical testing progresses toward becoming tedious and isn't adequate. Thus, one applies deformity situated (auxiliary) checking, as will be talked about in more detail as pursues.

We think checking is done by: decision of a great deal of deformations saw as the no doubt, the depiction of a ton of estimations, the assurance a collective set of checking centers (or yield signals) or more all, the association of activity tidal checking information is connected with the framework inputs taking into account recognize capacity and perceptibility of the recorded issue impacts. Here, economically implies that 1 check information is occupied whatever number blames as could reasonably be expected.

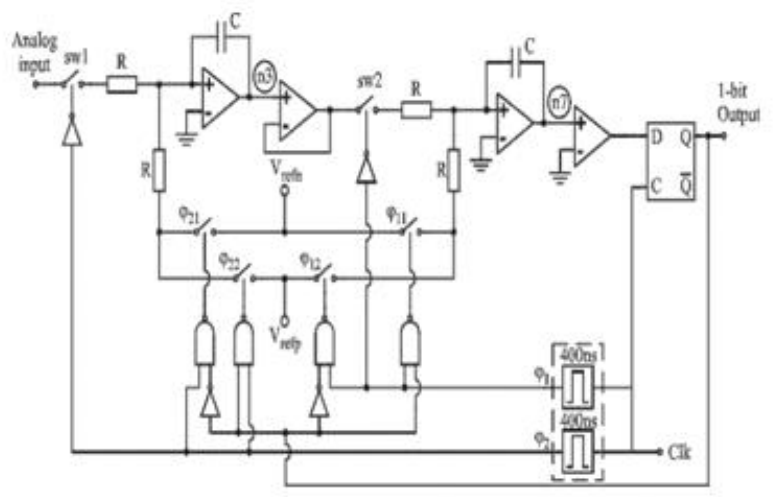

Fig 1. Circuit Diagram for $\Sigma-\Delta$ modulator.

Choice of the kind of estimations and checking set of values is explicit to perambulate. This shall be adhering to the computation which is required and are recommended to useful check. Explicit estimations, for example, supply current observing is much of the time embraced, as well. Separate test focuses might be included request to improve perceptibility or recognizability. Explicit structure for testability ideas can be connected.

After determination of test flags, the deficiency inclusion must be assessed. To do that, the same number of imitations of the first circuit as the quantity of anticipated flaws must be made. For expansive complex frameworks containing mechanical, analogue and advanced equipments, quantity is imitations winds up enormous. Every reproduction has one shortcoming embedded. The deficiency inclusion is assessed after reproduction of the flawed frameworks by com-paring the outcomes hence acquired along the reaction of the shortcoming free framework. In the event that these two vary, the deficiency is secured and the comparing section in the issue rundown will be eliminated. To decrease the calculation exertion, calculations has been explained to reenact various broken loop path agree recently in simple \& advanced spaces yet haven't in blended flag, blended portrayal frameworks.

\section{III. $\Sigma-\triangle$ CONVERTION TRANSITION ARCHITECTURE}

For example of a complex non-direct one of a kind electronic circuit with mixed signs, the structure of sigma-delta modulator is picked.

$\Sigma-\Delta$ convertion progresses are engaging for arrangement low repeat high-objectives easy to-cutting edge modifiers. The use coarse quantization is at any rate one info circles[8],[10],[12]. By inspecting at a repeat that is much more noticeable than the banner exchange speed, it is useful for the information circles to shape the quantization uproar with the objective that most by far of the distortion control are moved away from the banner band. Thus outer layer band uproar would have the option to be debilitated with a propelled channel. How much the quantization distortion will be diminished rely on upon the solicitation of the tumult framing and the oversampling extent [V].

Not with standing with flexibility non-idealities, oversampled analog to digital converters streamline structure mix by diminishing the mass basic equipment. Since they test the basic information movement over the any quist rate, precision test equipment is silly. Moreover, the heaviness is straightforward enemy of associating channel is altogether diminished. A lot of its capacity is exchanged to the computerized obliteration ch Artificial Neural Networked, which can be pl Artificial Neural Networked and produced to exact particulars, including a straight stage trademark.

\section{DEFECTS AND ERRORS IN CONVERTION TRANSITION}

For example of an unpredictable circuit, the $\sigma-\delta$ convertion progress in diagram is picked [III]. This is a mixed banner circumstance, basic \& propelled parts. Circuit breakers in the circuit are shown immaculate circuit breakers, with 0check for shut circuit breaker and unending restriction for $\mathrm{ON}$ circuit breaker [IV].

This sum of surface blaming period is ceaseless to check change to keep the expansion steady. This suggests the straightforward circuit breaker term paying little regard to clock period data and switch control square limits heartbeat to create sign of fixed time term. Fig. 2 demonstrates response of the framework when the information is energized sign.

The proposed work deals with the issues about modernized bit in the loop path are taken as a note. Propelled banner will give as "caught at-1" otherwise "stuck-at-0". From the loop path mentioned in the diagram, direct are obliged by front line signs, so there are sets of a similar insufficiency impacts, for example, the impact is a tantamount when the circuit breaker is close (Open) state and the reason yield are "got at-1" ("stuck - at-0"). Thusly, think about blames (which imply the clear piece of the circuit) as got circuit breakers[13],[15],[17]. 


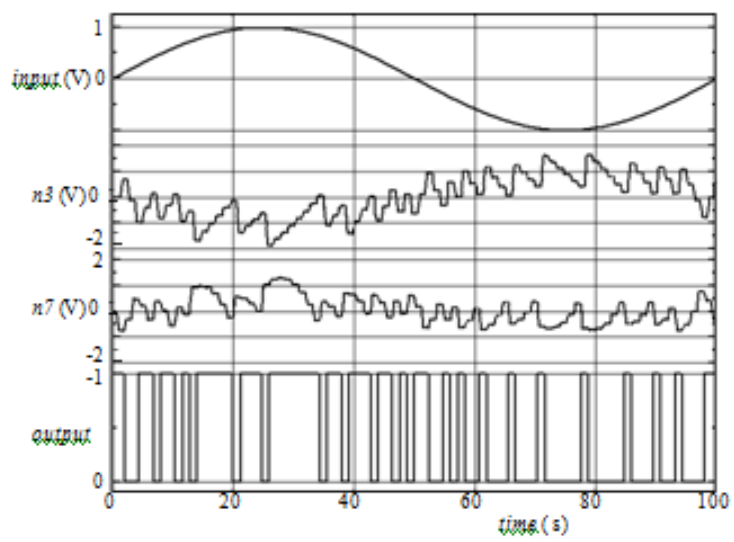

Fig2. Simulation results for linear sinusoidal excitation

Flaw word references are made utilizing for reaction in this circuit for information incline flag. We distributed one way to deal with shortcoming word reference creation, where yield signs of the deficiency free and of the broken circuits are changed utilizing the FFT in [VI] [14],[16],[18].

Table 1: Defect and error list

\begin{tabular}{|c|c|c|}
\hline $\begin{array}{c}\text { DIFFERENT } \\
\text { DEFECTS }\end{array}$ & Specifications & $\begin{array}{c}\text { DEFECT } \\
\text { SYMBOL }\end{array}$ \\
\hline Fast Forward & C9CA9 & A \\
\hline sw1OFF & 88888 & B \\
\hline$\square 12$ OFF & $38 E 38$ & C \\
\hline$\square 210 F F$ & 11111 & D \\
\hline$\square 22$ OFF & AAAAA & E \\
\hline sw1ON & 74466 & F \\
\hline$\square 110 F F$ & 0E18D & G \\
\hline sw2ON & F1E94 & H \\
\hline sw2OFF & FFFFF & I \\
\hline
\end{tabular}

This elective strategy mentioned, the model result regard are selected next each clock pluse, hence the yield propelled characteristics structure the yield signature. These are by then addressed in dynamically littler hexadecimal introduction. As necessities are, inadequacy word reference is made and seemed first coloum. In the principle portion of first column, eight picked lacks are named. Fast Forward speaks to the issue free circumstance.

This circumstances when circuit breaking in the analysis hover are forever closed are denied, in light of the fact that volt (V) represents Vrp-type and Vrn-type. This 2nd segment includes all imprints seen at the yield. The imprint is then coded as showed up in the third area. In the coding strategy we had as a fundamental need that amount feedback should not be same weakness symbol (for eg. FFFFF and 11111 (decimal regard is shown in framework as decimal regard an, or 9 as numerical regard 9). Artificial neural framework was set up for exhibiting the convey - into table. This can be exchanged with step- a -head neural system including 1 secured compartment. The structure of the system is appeared in chart three.
Table 2: Ann weights and thresholds

$\begin{array}{ll}\text { weight }(1,1)(2,1) & 120.812 \\ \text { weight }(1,2)(2,1) & -71.5911 \\ \text { weight }(1,3)(2,1) & -170.517 \\ \text { weight }(1,4)(2,1) & 145.099 \\ \text { weight }(1,5)(2,1) & 10.6883 \\ \text { weight }(1,1)(2,2) & 104.461 \\ \text { weight }(1,2)(2,2) & -85.9051 \\ \text { weight }(1,3)(2,2) & -181.814 \\ \text { weight }(1,4)(2,2) & 142.592 \\ \text { weight }(1,5)(2,2) & 5.02798 \\ \text { weight }(1,1)(2,3) & 118.426 \\ \text { weight }(1,2)(2,3) & -80.095 \\ \text { weight }(1,3)(2,3) & -166.541 \\ \text { weight }(1,4)(2,3) & 139.481 \\ \text { weight }(1,5)(2,3) & -8.45216 \\ \text { weight }(2,1)(3,1) & 14.4496 \\ \text { weight }(2,2)(3,1) & 10.0822 \\ \text { weight }(2,3)(3,1) & -14.6015 \\ & \\ \text { threshold }(2,1) & -18.3932 \\ \text { threshold }(2,2) & 5.31276 \\ \text { threshold }(2,3) & 0.747092 \\ \text { threshold }(3,1) & 0.25\end{array}$

This structure and the parameters of the obtained counterfeit neural system are affirmed by invigorating the fake neural system with flawed wellsprings of data. Reactions of the counterfeit neural system show that there were no bumbles in perceiving the issues what is shown in Table 3. Insignificant mistakes may be viewed (under 00.7\%)[19],[20].

Table 3: ARTIFICIAL NEURAL NETWORK output codes

\begin{tabular}{|c|c|c|}
\hline Type of fault & Fault symbol & $\begin{array}{l}\text { artificial } \\
\text { neural network } \\
\text { output }\end{array}$ \\
\hline $\mathrm{FF}$ & $A$ & 0.00754392 \\
\hline $\mathrm{Sw}_{1} \mathrm{OFF}$ & $B$ & 1.00436 \\
\hline$\square_{12} \mathrm{OFF}$ & $\mathrm{C}$ & 2 \\
\hline$\square_{21} \mathrm{OFF}$ & $\mathrm{D}$ & 2.99988 \\
\hline$\square_{22} \mathrm{OFF}$ & $\mathrm{E}$ & 4.00265 \\
\hline $\mathrm{Sw}_{1} \mathrm{ON}$ & $\mathrm{F}$ & 5.00078 \\
\hline$\square_{11} \mathrm{OFF}$ & $\mathrm{G}$ & 5.9999 \\
\hline $\mathrm{sw}_{2} \mathrm{ON}$ & $\mathrm{H}$ & 7.0013 \\
\hline $\mathrm{sw}_{2} \mathrm{OFF}$ & I & 8.00416 \\
\hline
\end{tabular}

The conclusion was effective. Albeit just the disastrous imperfections were analyzed in this model, delicate deficiencies can be effectively presented. As needs be, we may presume that artificial neural networks are helpful and ground-breaking implies for determination, and, what is significant, feasible as equipment that might be as quick as important to pursue the progressions of the framework's reaction progressively. 


\section{Fault Diagnosis In Mixed-Mode Circuit By Using Artificial Neural Network Method}

\section{CONCLUSION}

Artificial neural network approach is connected here, out of the blue, to analysis of disastrous deformities in an advanced piece of nonlinear blended mode circuit. We think about this outcome as a full achievement. Albeit just the calamitous deformities were analyzed in this model, delicate issues can be effectively presented. As needs be, we may presume that artificial neural networks are advantageous and ground-breaking implies for determination, and, what is significant, feasible as equipment that might be as quick as important to pursue the progressions of the framework's reaction progressively.

The extended work will be given to implementation of this plan to finish set of deficiencies that incorporate blames in simple and the computerized part. Cataclysmic just as delicate faults are expected to be presented.

\section{REFERENCES}

1. Kongkham, D. \& Sundararajan, M. 2019, "Distributed wideband sensing method for faded dynamic spectrum access", International Journal of Innovative Technology and Exploring Engineering, vol. 8 , no. 10, pp. 4309-4312.

2. Balaji, S., John Paul Praveen, A. \& Mohanraj, R. 2019 "Recognizable proof and analysis of palm print in biometric authentication system using bayes techniques", International Journal of Innovative Technology and Exploring Engineering, vol. 8, no. 9 Special Issue 3, pp. 1126-1129.

3. Kavitha, G., Priya, N., Velvizhi, R. \& Allin Geo, A.V. 2019, "Paralle computation in correspondence and signal processing", International Journal of Innovative Technology and Exploring Engineering, vol. 8 , no. 9 Special Issue 3, pp. 1136-1139.

4. Hema, R., Sundararajan, M. \& Balaji, S. 2019, "Smartphone control robot with automatic firing gun", International Journal of Innovative Technology and Exploring Engineering, vol. 8, no. 9 Special Issue 3, pp. 625-627.

5. Kaliyamurthie, K.P., Sundar Raj, B., Velvizhi, R. \& Shanmugapriya, K. 2019, "Dual band paper substrate CPW antenna for wireless applications", International Journal of Innovative Technology and Exploring Engineering, vol. 8, no. 9 Special Issue 3, pp. 605-608.

6. Geo, A.V.A., Arunachalam, A.R., Michael, G. \& Elankavi, R. 2019, "Evaluating architecture using compact modalities", International Journal of Innovative Technology and Exploring Engineering, vol. 8, no. 9 Special Issue 3, pp. 836-838.

7. Theivasigamani, S., Jeyapriya, D. \& Anita Davamani, K. 2019 "Anamoly analyzing and exploring for wireless sensor networks", International Journal of Innovative Technology and Exploring Engineering, vol. 8, no. 9 Special Issue 3, pp. 1116-1118.

8. Jeyapriya, D., Theivasigamani, S., Velvizhi, R. \& Nandhini, P. 2019, "Program detection in wireless feeler networks", International Journal of Innovative Technology and Exploring Engineering, vol. 8, no. 9 Special Issue 3, pp. 1194-1195.

9. Gowri Sankaran, B., Karthik, B. \& Vijayaragavan, S.P. 2019, "Image compression utilizing wavelet transform", International Journal of Innovative Technology and Exploring Engineering, vol. 8, no. 10, pp. 4305-4308.

10. Gowri Sankaran, B., Karthik, B. \& Vijayaragavan, S.P. 2019, "Weight ward change region plummeting change for square based image huffman coding", International Journal of Innovative Technology and Exploring Engineering, vol. 8, no. 10, pp. 4313-4316

11. Hema, R., Sundararajan, M. \& Balaji, S. 2019, "Smartphone control robot with automatic firing gun", International Journal of Innovative Technology and Exploring Engineering, vol. 8, no. 9 Special Issue 3 , pp. 625-627.

12. Rangaswamy, K. \& Rajabhushanam, C. 2019, "Congestion control in wireless network using TCP friendly rate control (TFRC)", International Journal of Recent Technology and Engineering, vol. 8, no. 2 Special issue 3, pp. 1598-1602.

13. Tamil Selvan, S. \& Sundararajan, M. 2019, "Performance Parameters of 3 Value 8t Cntfet Based Sram Cell Design Using H-Spice",
International Journal of Recent Technology and Engineering, vol. 8 , no. 2 Special issue 5, pp. 22-27.

14. Vinoth, V.V. \& Kanniga, E. 2019, "Steganographical techniques in hiding text images - system", International Journal of Recent Technology and Engineering, vol. 8, no. 2, pp. 6535-6537.

15. Saravana, S., Balaji, S., Arulselvi, S. \& John Paul Praveen, A. 2019, "Reliable power quality monitoring and protection system", International Journal of Innovative Technology and Exploring Engineering, vol. 8, no. 9 Special Issue 3, pp. 644-645.

16. Sundaramoorthy, A. \& John Wiselin, M.C. 2019, "Single patch antenna with multiple feed", International Journal of Innovative Technology and Exploring Engineering, vol. 8, no. 9, pp. 1743-1747.

17. Velavan, R., Bharanidharan, S. \& Sheeba, B. 2019, "EMF pollution Causes, effects and protection", International Journal of Innovative Technology and Exploring Engineering, vol. 8, no. 9 Special Issue 3, pp. 1166-1168.

18. Veer, R.A., Arulselvi, S. \& Karthik, B. 2019, "Construction of ensemble square classification approaches in MIMO OFDM", International Journal of Engineering and Advanced Technology, vol. 8, no. 5, pp. 2039-2041.

19. Agitha, W. \& Kaliyamurthie, K.P. 2019, "Improved energy efficient in WBAN using MAC with cloud computing", International Journal of Innovative Technology and Exploring Engineering, vol. 8, no. 8, pp. 2405-2408.

20. Kastro, G.G. \& Wiselin, M.C.J. 2019, "Design and analysis of stub loaded resonator", International Journal of Recent Technology and Engineering, vol. 8, no. 1 Special Issue4, pp. 272-283.

\section{AUTHORS PROFILE}

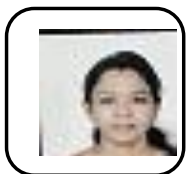

S. Ramya Assistant Professor, Department of Electronics and Communication Engineering, Bharath Institute of Higher Education and Research, Chennai, India.

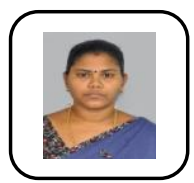

M.Meenaakumari, Assistant Professor, Department of Electronics and Communication Engineering, Bharath Institute of Higher Education and Research, Chennai, India.

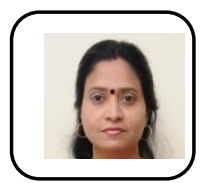

R. Hema, Assistant Professor, Department of Electronics and Communication Engineering, Bharath Institute of Higher Education and Research, Chennai, India. 